\title{
Determination of the temperature distribution in a minichannel using ANSYS CFX and a procedure based on the Trefftz functions
}

\author{
Beata Maciejewska ${ }^{1, *}$, Stawomir Błasiak $^{2}$, Magdalena Piasecka ${ }^{2}$ \\ ${ }^{1}$ Faculty of Management and Computer Modelling \\ ${ }^{2}$ Faculty of Mechatronics and Mechanical Engineering \\ Kielce University of Technology, Al. 1000-lecia P.P. 7, 25-314 Kielce, Poland
}

\begin{abstract}
This work discusses the mathematical model for laminar-flow heat transfer in a minichannel. The boundary conditions in the form of temperature distributions on the outer sides of the channel walls were determined from experimental data. The data were collected from the experimental stand the essential part of which is a vertical minichannel $1.7 \mathrm{~mm}$ deep, $16 \mathrm{~mm}$ wide and $180 \mathrm{~mm}$ long, asymmetrically heated by a Haynes-230 alloy plate. Infrared thermography allowed determining temperature changes on the outer side of the minichannel walls. The problem was analysed numerically through either ANSYS CFX software or special calculation procedures based on the Finite Element Method and Trefftz functions in the thermal boundary layer. The Trefftz functions were used to construct the basis functions. Solutions to the governing differential equations were approximated with a linear combination of Trefftz-type basis functions. Unknown coefficients of the linear combination were calculated by minimising the functional. The results of the comparative analysis were represented in a graphical form and discussed.
\end{abstract}

\section{Introduction}

Recent advances in technology have produced devices with mini spaces. The trend toward miniaturization of components is the driving force behind better cooling technologies designed to prevent going over the maximum allowable operating temperatures. Phasechange processes, such as flow boiling, are very important for their ability to provide highest possible heat fluxes at a low temperature difference between a heated surface and a boiling liquid over a small heat transfer area. Extensive efforts to recognize boiling phenomena in small channels include theoretical analyses based on experimental measurements. The results can be applied to the construction of devices with minichannels and in heating, cooling, thermostabilization and thermoregulation applications.

\section{Main aim}

This work discusses a mathematical model of the heat transfer occurring between the flowing coolant, minichannel walls and surroundings. The boundary conditions in the form of temperature distributions on the outer sides of the minichannel walls were determined from the experimental measurement data The problem was analysed numerically using either the ANSYS CFX program or special calculation procedures based on the finite element method and Trefftz functions [5-16] in the thermal boundary layer.

\section{Experimental data}

The essential part of the experimental rig is a measurement module with a vertical rectangular minichannel, $1.7 \mathrm{~mm}$ deep, $16 \mathrm{~mm}$ wide and $180 \mathrm{~mm}$ long. The working fluid flowing in the minichannel is Flourinert FC-72. The schematic diagram of the measurement module is shown in figure 1 . The heated wall of the minichannel is a metal plate made of Haynes230 alloy, about $0.45 \mathrm{~mm}$ thick. The other wall of the minichannel is a $6 \mathrm{~mm}$ thick stainless steel (unheated) plate. Temperatures on the minichannel walls outer surfaces were measured simultaneously using infrared thermography. The temperature of the heated plate was monitored with the aid of the FLIR E60 infrared camera and the unheated plate - with the FLIR SC640 infrared camera. Before each experimental series, the metal plates were coated with a black paint to achieve an emissivity of 0.83 [1]. K-type thermocouples and pressure converters were installed at the inlet and outlet of the minichannel.

The flow loop comprises (besides the measurement module): a gear pump, a compensating tank, a tube-type heat exchanger, a filter, a Coriolis mass flowmeter and a deaerator. A data acquisition station and a computer with appropriate software were used for experimental data

Corresponding author: beatam@tu.kielce.pl

C The Authors, published by EDP Sciences. This is an open access article distributed under the terms of the Creative Commons Attribution License 4.0 (http://creativecommons.org/licenses/by/4.0/). 
collection. The supply and control system consists of an inverter welder, shunt, ammeter and a voltmeter. The experimental rig is presented in [1-4].

During experiment, there is a FC-72 Fluorinert laminar flow in a minichannel. Data for the selected setting of the heat flux supplied to the heated plate during subcooled boiling is analysed. In the subcooled boiling region, the liquid flowing in the minichannel was superheated at the interface with the heated plate and subcooled at the core of the flow. The experimental thermal and flow parameters, physical properties of the heated minichannel wall (made of Haynes-230) and the properties of the working fluid (Fluorinert FC-72) for this setting are taken to be the same in the two calculation approaches and shown in Table 1.

Table 1. Main experimental thermal and flow parameters, physical properties of Haynes-230 and FC-72 properties.

\begin{tabular}{|c|c|}
\hline \multicolumn{2}{|c|}{ Main thermal and flow experimental parameters } \\
\hline Volumetric heat flux & $1.22 \cdot 10^{5} \mathrm{~kW} \mathrm{~m}^{-3}$ \\
\hline Flow velocity & $0.2 \mathrm{~m} \mathrm{~s}^{-1}$ \\
\hline Mass flux & $344 \mathrm{~kg} \mathrm{~m}^{-2} \mathrm{~s}^{-1}$ \\
\hline Reynolds number & 1846 (laminar flow) \\
\hline Fluid temperature at the inlet & $14.3 \mathrm{C}$ \\
\hline Fluid temperature at the outlet & $25.2 \mathrm{C}$ \\
\hline Pressure at the inlet & $89.9 \mathrm{kPa}$ \\
\hline Inlet liquid subcooling & $39 \mathrm{C}$ \\
\hline \multicolumn{2}{|c|}{$\begin{array}{l}\text { Physical properties of the heated plate } \\
\text { (made of Haynes-230) }\end{array}$} \\
\hline Density & $8970 \mathrm{~kg} \mathrm{~m}^{-3}$ \\
\hline Thermal conductivity & $9.7 \mathrm{~W} \mathrm{~m}^{-1} \mathrm{~K}^{-1}$ \\
\hline Specific Heat & $397 \mathrm{~J} \mathrm{~kg}^{-1} \mathrm{~K}^{-1}$ \\
\hline \multicolumn{2}{|c|}{$\begin{array}{l}\text { Physical properties of the unheated plate } \\
\text { (made of stainless steel) }\end{array}$} \\
\hline Density & $7750 \mathrm{~kg} \mathrm{~m}^{-3}$ \\
\hline Thermal conductivity & $15.1 \mathrm{~W} \mathrm{~m}^{-1} \mathrm{~K}^{-1}$ \\
\hline Specific Heat & $480 \mathrm{~J} \mathrm{~kg}^{-1} \mathrm{~K}^{-1}$ \\
\hline \multicolumn{2}{|c|}{ Physical properties of the working fluid (FC-72) } \\
\hline Liquid density & $1737 \mathrm{~kg} \mathrm{~m}^{-3}$ \\
\hline Dynamic viscosity & $0.0006918 \mathrm{~Pa} \mathrm{~s}$ \\
\hline Liquid Specific Heat & $1044 \mathrm{~J} \mathrm{~kg}^{-1} \mathrm{~K}^{-1}$ \\
\hline Liquid Thermal Conductivity & $0.0561 \mathrm{~W} \mathrm{~m}^{-1} \mathrm{~K}^{-1}$ \\
\hline
\end{tabular}

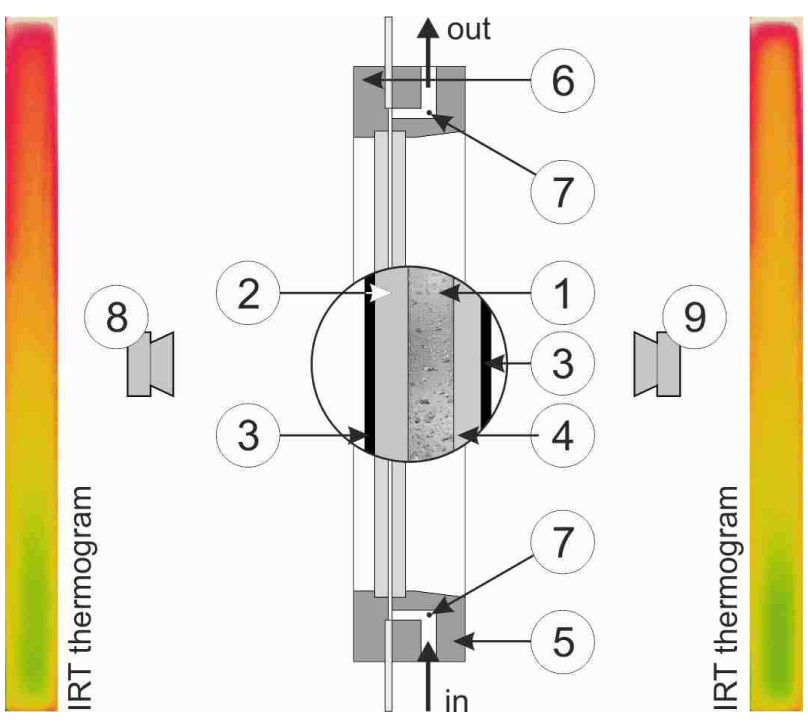

Fig. 1. The schematic diagram of the measurement module: 1-minichannel, 2-heated plate, 3-black paint with known emissivity, 4-unheated plate, 5-channel body, 6-front cover, 7-thermocouple, 8,9 - infrared cameras

\section{Numerical methodology}

\subsection{The mathematical formulation}

Two-dimensional steady-state heat flow in the minichannel is assumed. Temperature variation along the minichannel width is negligible for this study. The $x$ dimension along the flow direction and the $y$ dimension perpendicular to the flow direction (related to the thickness of the heated plate) are considered.

The boundary-value problem is described in two adjacent regions by:

- Poisson's equation in the heated plate [12]:

$$
\nabla^{2} T_{p_{-} h}=-\frac{I \cdot \Delta U}{A \cdot \delta_{p_{-} h} \cdot \lambda_{p_{-} h}} \text { for }(x, y) \in \Omega_{p_{-} h}
$$

- Fourier-Kirchhoff's equation in the thermal boundary layer of the fluid [16]:

$$
\frac{\lambda_{f}}{c_{p} \rho} \nabla^{2} T_{f}=w_{x}(y) \frac{\partial T_{f}}{\partial x}-\text { for }(x, y) \in \Omega_{T}
$$

The boundary conditions have the form:

$$
\begin{gathered}
T_{p_{-} h}(0, y)=T_{p_{-} h}^{1} \\
T_{p_{-} h}(L, y)=T_{p_{-} h}^{P_{P}} \\
\lambda_{p_{-} h} \frac{\partial T_{p_{-} h}}{\partial y}(0, y)=q_{\text {loss }} \\
T_{p_{-} h}\left(x_{m}, 0\right)=T_{p_{-} h}^{m} \text { for } m=1,2, \ldots, P_{h} \\
T_{l}\left(x, \delta_{p_{-} h}\right)=T_{p_{-} h}\left(x, \delta_{p_{-} h}\right)
\end{gathered}
$$




$$
\begin{gathered}
T_{l}(0, y)=T_{l}^{i n} \text { for } \delta_{p_{-} h}<y<\delta_{p_{-} h}+\delta_{T} \\
T_{l}(L, y)=T_{l}^{\text {out }} \text { for } \delta_{p_{-} h}<y<\delta_{p_{-} h}+\delta_{T}
\end{gathered}
$$

where $\Omega_{p_{-} h}=\left\{(x, y) \in R^{2}: 0<x<L, \quad 0<y<\delta_{p_{-} h}\right\}$, $\Omega_{T}=\left\{(x, y) \in R^{2}: 0<x<L, \quad \delta_{p_{-} h}<y<\delta_{p_{-} h}+\delta_{T}\right\}$, $T_{p_{-} h}-$ the heated plate temperature, $T_{f}-$ the fluid temperature, $L$ - length of the minichannel, $I$ - current, $\Delta U$ - voltage drop, $A-$ surface area of the heated plate, $P_{h}$ - the number of measurements obtained using infrared thermography (IRT) on the outer surface of the heated plate, $T_{p h}^{m}$ - the heated plate temperature measured by infrared thermography at the boundary $y=0, q_{\text {loss }}$ - heat loss to the surroundings calculated as in [1], $\delta_{p_{-} h}-$ heated plate thickness, $\delta_{T}-$ the thickness of the thermal boundary layer [16], $\lambda_{p_{-} h}-$ coefficient of thermal conductivity of the heated plate, $\lambda_{f}-$ coefficient of thermal conductivity of the fluid, $c_{p}-$ specific heat of the fluid, $\rho$-density of the fluid $w_{x}(y)$ - component of vector liquid velocity, parallel to the minichannel heated surface [16].

\subsection{The use of Trefftz functions}

In each element $\Omega_{j}, j=1,2, \ldots, L 1 \cdot L 2$ of the domain $\Omega=\Omega_{p_{-} h} \cup \Omega_{T}$, the system of equations (1-9) was solved. The approximate temperature $T_{p_{-} h}$ was given by:

$$
T_{p_{-} h}^{j}(x, y)=u(x, y)+\sum_{k=1}^{N}\left(\widehat{T}^{n}-u\left(x_{n}, y_{n}\right)\right) f_{j k}(x, y)
$$

the fluid approximate temperature was described by the expression:

$$
T_{f}^{j}(x, y)=\sum_{k=1}^{N} \widehat{T}^{n} g_{j k}(x, y)
$$

where: $u(x, y)$ - the particular solution of Eq. (1), $f_{j k}(x, y$,$) - the basis functions determined as linear$ combinations of the Trefftz functions according to Laplace's equation [9], $g_{j k}(x, y)$ - the basis functions referred to the Fourier-Kirchhoff equation (the Trefftz functions that satisfy the Fourier-Kirchhoff equation are given in [16]), $\widehat{T}^{n}$ - the unknown temperature in the $n$-th node of domain $\Omega, j$ - element number, $k$ - basis function number in $j$-th element, $n$ - node number in the entire domain $\Omega, N$ - the number of nodes in the element, $L 1$ - the number of elements in the $x$-axis direction and $L 2$ - the number of elements in the $y$-axis direction.

To find unknown coefficients $\widehat{T}^{n}$, the appropriate functional was minimized [1].

\subsection{The use of the ANSYS CFX program}

The conditions (3)-(9) and equality of heat fluxes on the contact surface between the heated plate and the fluid were taken into account in the computational module by using the Conservative Interface Flux option for fluidsolid interfaces. The calculation results from solving the presented model on boiling heat transfer during FC-72 flow in a rectangular minichannel with the ANSYS CFX are shown to compare with results obtained from a special calculation procedure based on the FEM and Trefftz functions (presented in the previous chapter).

Numerical calculations were performed in the ANSYS CFX environment. The shape of the minichannel with the flowing fluid and its structural elements, i.e., the $0.45 \mathrm{~mm}$ thick heated plate and the $6 \mathrm{~mm}$ thick unheated plate restraining the channel space, were modelled with the aid of the Geometry-Design Modeler, as shown in figure 2.

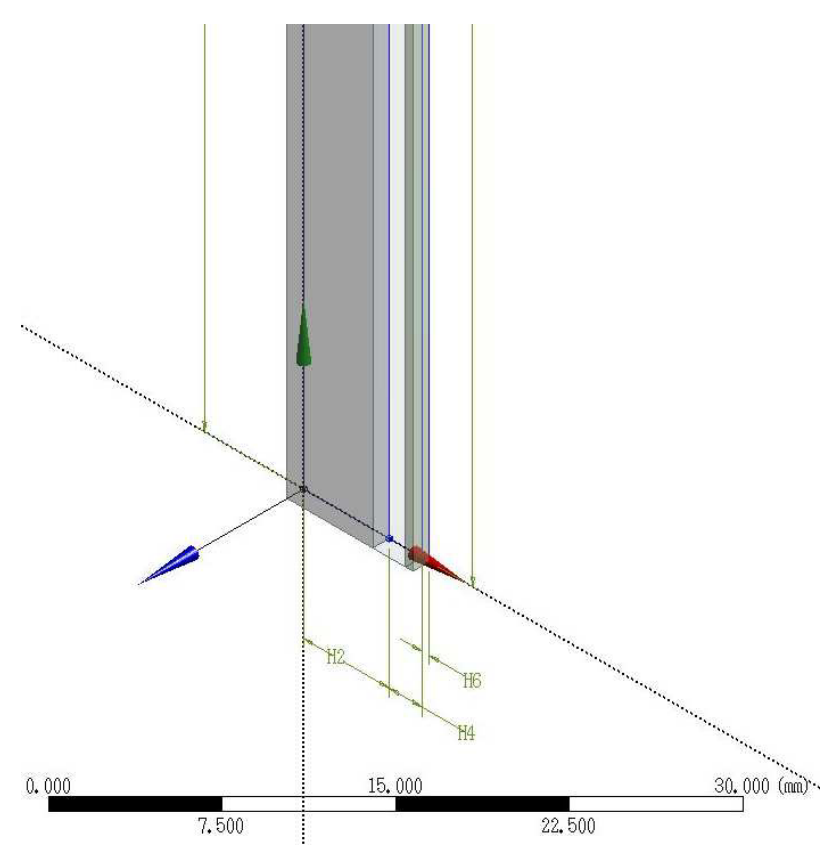

Fig. 2. The schematic diagram of the measurement module in Geometry-Design Modeler.

The next stage involved generating a mesh in all elements of the measurement module model. The Advanced Size function was used with the criteria based on Proximity and Curvature, with parameters as in figure 3 .

The mesh consisted of 589138 elements and 716940 nodes. For the sake of the character of numerical calculations and the need to combine the heat transfer phenomena in solids (the heated plate and the unheated plate), the computational module according to the project schematic was used, as shown in figure 4. 


\begin{tabular}{|l|l|}
\hline Use Advanced Size Function & On: Proximity and Curvature \\
\hline Relevance Center & Fine \\
\hline Initial Size Seed & Full Assembly \\
\hline Smoothing & High \\
\hline Transition & Fast \\
\hline Span Angle Center & Fine \\
\hline$\square$ Curvature Normal Angle & Default $\left(12.0^{\circ}\right)$ \\
\hline$\square$ Num Cells Across Gap & 6 \\
\hline Proximity Size Function ... & Faces and Edges \\
\hline$\square$ Min Size & $5 . \mathrm{e}^{-005 ~ m}$ \\
\hline$\square$ Proximity Min Size & Default (1.8017e-005 m) \\
\hline$\square$ Max Face Size & $5 . \mathrm{e}^{-004} \mathrm{~m}$ \\
\hline$\square$ Max Size & $5 . \mathrm{e}^{-003} \mathrm{~m}$ \\
\hline$\square$ Growth Rate & Default (1.50) \\
\hline Minimum Edge Length & $4.5 \mathrm{e}^{-004} \mathrm{~m}$ \\
\hline
\end{tabular}

Fig. 3. The details of the mesh.

Another stage of preparing numerical calculations in ANSYS Workbanch involved determining boundary conditions, which were adopted in compliance with the relationships described in Chapter 4, formulas (3)-(9). The boundary conditions being the temperature distributions along the outer wall of the heated plate and the unheated plate were taken from the experimental data and used in the Fluid Flow (CFX) module in the form as shown in figure 5.

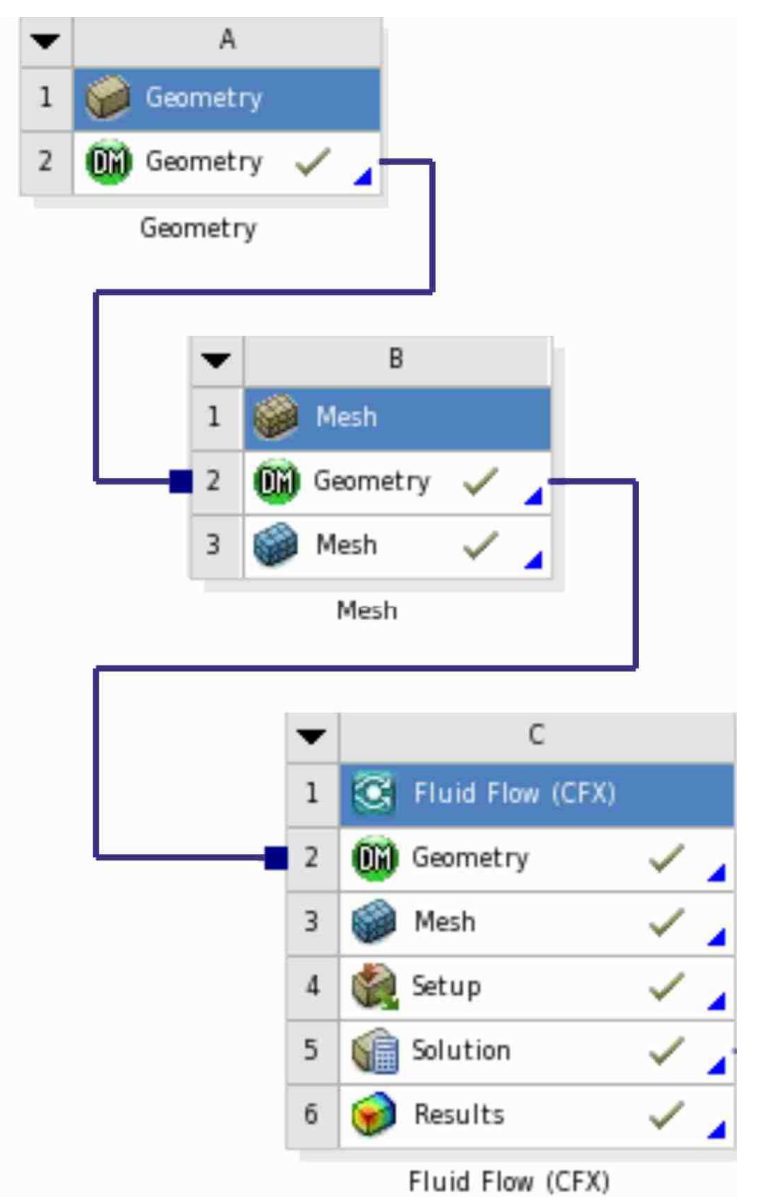

Fig. 4. The project schematic. a)

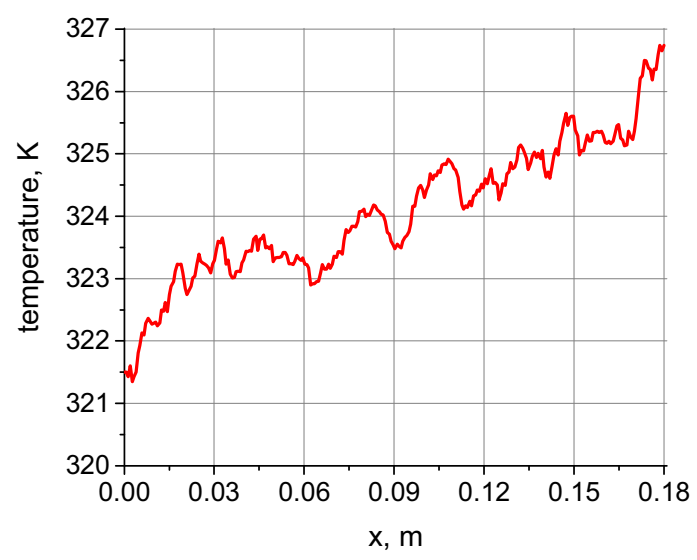

b)

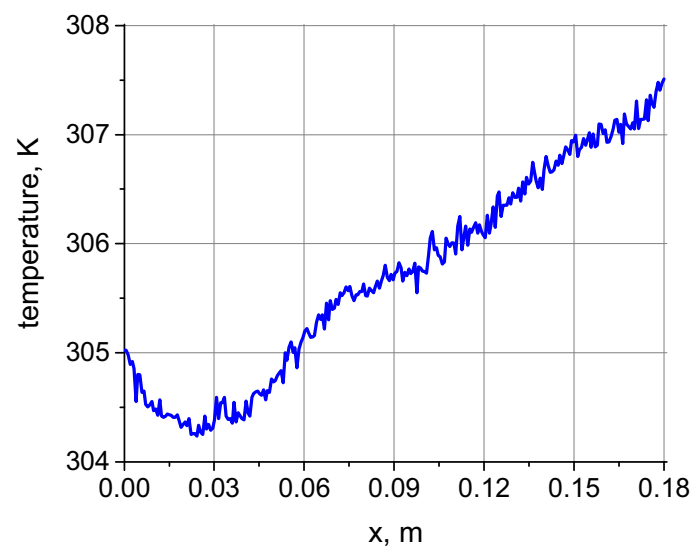

Fig. 5. Experimental measurement data: a) temperature of the heated plate, $b$ ) temperature of the unheated plate.

\section{Results and discussion}

The results are presented graphically in figure 6 as relationship between temperature and the distance from the minichannel inlet to compare the values calculated using the Trefftz functions (red points) from with that obtained using the ANSYS software (blue points), at $\delta_{\mathrm{M}} / 40$ distance, where $\delta_{\mathrm{M}}$ denotes the minichannel depth. Results obtained near the heated plate-fluid boundary, which is comprised of a thermal boundary layer, indicates that the temperature distribution calculated using the Trefftz functions and obtained using the ANSYS software are very similar. The temperatures increased slightly with the distance from the minichannel inlet and their values are high, similarly to the heated plate temperature measured from infrared thermography.

Minor differences in the results may be due to:

- $\quad$ simplifications used in the mathematical model (1)(9) relative to the ANSYS CFX model (a laminar model governed by the Navier-Stokes equations which describe the processes of momentum, heat and mass transfer);

- the use of various approximate calculation methods in ASNYS CFX and the FEM based on Trefftz functions. 
It should be added that the subcooled boiling region took place during experiments. In this region temperatures are relatively low, as the heat transfer coefficient $[1,3,4]$.

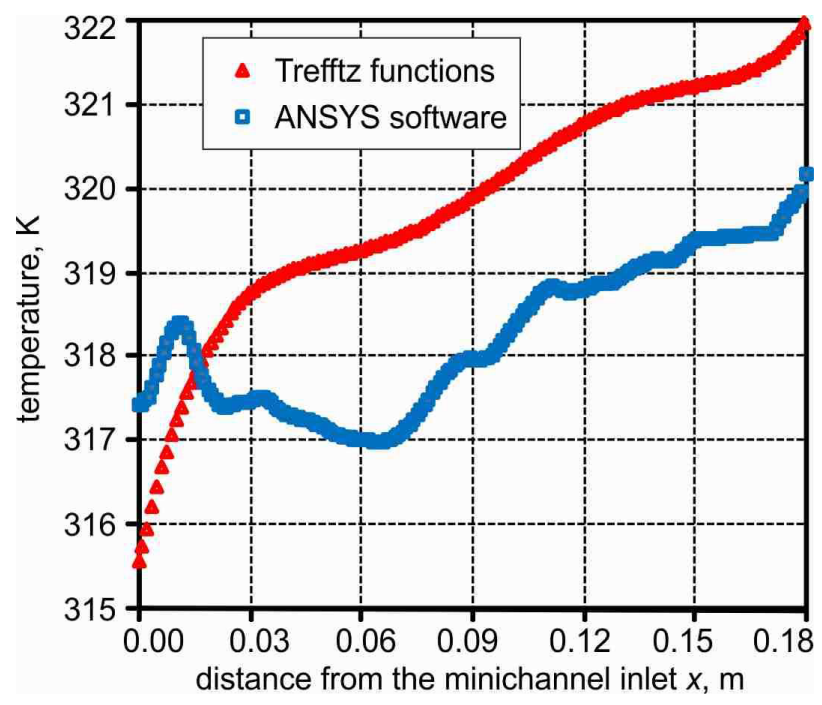

Fig. 6. Temperature vs. the minichannel length, obtained using the Trefftz functions (red points) and the ANSYS software (blue points), generated at $\delta_{\mathrm{M}} / 40$ distance on the minichannel depth from the foil-fluid boundary.

\section{Conclusions}

This work discusses the mathematical model for laminar-flow heat transfer in a minichannel. The boundary conditions in the form of temperature distributions on the outer sides of the channel walls were determined from experimental data. The data were collected from the experimental stand the essential part of which is a vertical minichannel $1.7 \mathrm{~mm}$ deep, $16 \mathrm{~mm}$ wide and $180 \mathrm{~mm}$ long, asymmetrically heated by a Haynes-230 alloy plate. Infrared thermography allowed determining temperature changes on the outer side of the minichannel walls. The problem was analysed numerically through either ANSYS CFX software or special calculation procedures based on the Finite Element Method and Trefftz functions. Results were presented graphically as temperature vs. the minichannel length, near the heated plate-fluid boundary, which is comprised of a thermal boundary layer. The temperature distributions calculated using the Trefftz functions and obtained using the ANSYS software were very similar.

\section{ACKNOWLEDGMENTS}

The research reported herein was supported in part by a grant from the Polish National Science Centre (No. DEC2013/09/B/ST8/02825).

\section{References}

1. M. Piasecka, K. Strąk, B. Maciejewska, Heat Transf. Eng. 38 (3), 332-346 (2017)

2. M. Piasecka, Int. J. Refrig. 56, 198-212 (2015)
3. M. Piasecka, B. Maciejewska, Exp. Therm. Fluid Sci. 68, 459-467 (2015)

4. M. Piasecka, Int. J. Heat Mass Transf. 81, 114-121 (2015)

5. E. Trefftz, Proc. Int. Kongress für Technische Mechanik, Zürich, 131-137 (1926)

6. I. Herrera, Meth. Partial Diff. Eqs., 16, 561-580 (2000)

7. K. Grysa, A. Maciąg, A. Pawińska, Int. J. Heat Mass Transf., 55, 7336-7340 (2012)

8. M. J. Ciałkowski, A. Frąckowiak, J. Therm. Sci., 11, 148-162 (2002)

9. M. J. Ciałkowski, J. Therm. Sci., 11, 163-171 (2002)

10. M. J. Ciałkowski, K. Grysa, J. Inv. Ill-Posed Prob., 18, 595-616 (2010)

11. K. Grysa, B. Maciejewska, J. Theor. Appl. Mech., 51, 251-264 (2013)

12. S. Hozejowska, R. Kaniowski, M. E. Poniewski, Int. J. Num. Methods Heat Fluid Flow, 24, 811-824 (2014)

13. A. Maciąg, Int. J. Num. Meth. Biomed. Eng., 27, 1107-1125 (2011)

14. S. Blasiak, A. Pawinska, Int. J. Heat Mass Transf., 90, 710-718 (2015)

15. B. Maciejewska, M. Piasecka, Heat Mass Transf., DOI: 10.1007/s00231-016-1895-1 (2016)

16. S. Hożejowska, J.Theor. Appl. Mech, 53, 969-980 (2015)

17. M. Piasecka, D. Michalski, K. Strąk, The European Physical J. Web Conf. 114, paper No. 02094 (2015) 